SUBJECT AREAS: ELECTRONIC MATERIALS

SELF-ASSEMBLY

ELECTRONIC DEVICES

Received

3 March 2014

Accepted

24 June 2014

Published

16 July 2014

Correspondence and requests for materials should be addressed to

W.W.H.W.

(wwhwong@unimelb.

edu.au)

\section{Hydrogen bonding in bulk heterojunction solar cells: A case study}

\author{
Zeyun Xiao, Kuan Sun, Jegadesan Subbiah, Shaomin Ji, David J. Jones \& Wallace W. H. Wong
}

School of Chemistry, Bio21 Institute, the University of Melbourne, 30 Flemington Road, Parkville, Victoria 3010, Australia.

Small molecules with dithieno[3,2-b;2', $\mathbf{3}^{\prime}$-d] thiophene as central building block and octyl cyanoacetate and octyl cyanoacetamide as different terminal building blocks have been designed and synthesized. The amide containing small molecule can form intermolecular hydrogen bonding between $\mathrm{N}-\mathrm{H} . . . \mathrm{O}=\mathrm{C}$ of the amide group. The photovoltaic properties and active layer morphologies of the two molecules in bulk heterojunction solar cells are compared to study the influence of hydrogen bonding on the active layer morphology. New methanofullerene compound containing amide group has also been synthesized and compared with conventional fullerene electron acceptors.

\begin{abstract}
$\Lambda$ ctive layer morphology is of key importance in bulk heterojunction (BHJ) solar cells. Bi-continuous nanoscale domains of donor and acceptor materials are required for efficient charge separation and transport $^{1-7}$. To achieve the optimum active layer morphology, various methods, such as thermal annealing, solvent annealing, solvent additives, have been used in the process of solar cells fabrication ${ }^{1-7}$. From a molecular point of view, chemists want to use self assembly or self organization to control the morphology by molecular design ${ }^{8-13}$. In this respect, hydrogen bonding is the first choice due to its strong intermolecular interaction, high selectivity and directionality ${ }^{14-17}$. In some cases, improved device performance had been demonstrated when hydrogen bonding was employed in $\mathrm{BHJ}$ solar cells ${ }^{18-22}$. Here, we describe a case study in which the performance of two similar small molecular donor materials, one with amide group to form intermolecular hydrogen bonding, the other with ester group, are compared in $\mathrm{BHJ}$ solar cells. In addition, an amide containing
\end{abstract} fullerene derivative was also synthesized and used in conjunction with the donor materials in devices.

A common design rule for the small molecule donor material is connecting central building blocks and terminal electron withdrawing units with an oligothiophene linker ${ }^{23-28}$. Based on our previous work ${ }^{29}$,

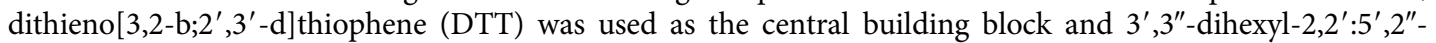
tertthiophene ${ }^{13}$ was used as the linkage. Octyl cyanoacetate and octyl cyanoacetamide served as electron withdrawing groups to end cap the small molecules (Figure 1). Octyl cyanoacetamide will lead to a Knoevenagel condensation product which is capable of strong hydrogen bonding. Synthesis of the targeted small molecules started from $3^{\prime}, 3^{\prime \prime}$-dihexyl-2,2':5',2'-tertthiophene-5-carbaldehyde ${ }^{13}$, compound 1 . Bromination of compound 1 with NBS provided compound 2 which reacted with bistrimethyltin DTT (compound 3) by Stille coupling reaction to afford compound 4 . Then compound 4 was converted to M1 and M2 by Knoevenagel condensation with octyl cyanoacetate and octyl cyanoacetamide respectively (Figure 2). It should be noted that M1 can be obtained in the presence of triethylamine, but M2 can only be synthesized in the presence of stronger base such as 1,8-diazabicyclo[5.4.0] undec-7-ene (DBU). The detailed synthetic procedures for M1 and M2 are described in Supplementary Information. Both products showed good solubility in common organic solvents such as tetrahydrofuran, dichloromethane, chloroform, chlorobenzene and dichlorobenzene. M1 and M2 were fully characterized with ${ }^{1} \mathrm{H}$ and ${ }^{13} \mathrm{C}$ NMR spectroscopy, mass spectrometry and elemental analysis.

The presence of hydrogen bonding moieties on the electron acceptor fullerene derivatives may provide further insights into the effect of hydrogen bonding on BHJ solar cell devices. As with the electron donor material, the acceptor should ideally phase separate on a suitable length scale to allow maximum ordering and thus charge can transport effectively in continuous pathways to the electrodes and the recombination of free charges can be minimized $^{6}$. In this regard, an analogue of $[6,6]$-phenyl- $\mathrm{C}_{61}$-butyric acid methyl ester $\left(\mathrm{PC}_{61} \mathrm{BM}\right)$ with an amide group was also designed and synthesized (see SI for details), resulting in $[6,6]$-phenyl- $\mathrm{C}_{61}-N$-methyl butyramide $\left(\mathrm{PC}_{61} \mathrm{MBA} \text {, Figure } 1\right)^{19}$.

\section{Results and Discussion}

The intermolecular hydrogen bonding of $\mathbf{M} 2$ and $\mathbf{P C}_{61} \mathbf{M B A}$. The amide group of the small molecule M2 made it possible for the formation of intermolecular hydrogen bonding which was first observed in solution by ${ }^{1} \mathrm{H}$ NMR 


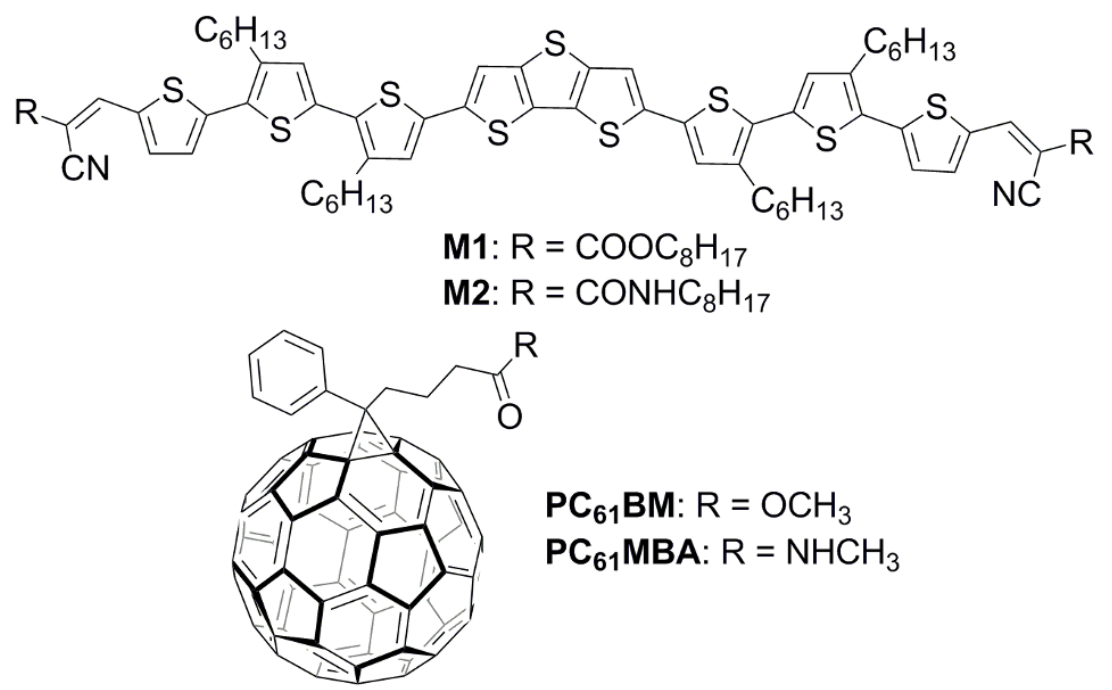

Figure $1 \mid$ Chemical structures of $\mathrm{M} 1, \mathrm{M} 2, \mathrm{PC}_{61} \mathrm{BM}$ and $\mathrm{PC}_{61} \mathrm{MBA}$.

dilution experiment (Figure 3). As the concentration increased, the chemical shift of the amide proton as well as the adjacent protons shifted indicating the aggregation of M2. This phenomenon was not observed in M1. In the solid film infrared (IR) spectrum of M2, the $\mathrm{N}-\mathrm{H}$ and $\mathrm{C}=\mathrm{O}$ stretching frequencies were at $3358 \mathrm{~cm}^{-1}$ and $1664 \mathrm{~cm}^{-1}$ respectively. These IR stretching frequencies indicated hydrogen bonding in the solid state sample of $\mathbf{M} 2^{30,31}$. Thermal behavior of M1 and M2 was examined using differential scanning calorimetry (DSC). Interestingly, the melting point $\left(\mathrm{T}_{\mathrm{m}}=168^{\circ} \mathrm{C}\right)$ and the crystallization temperature $\left(\mathrm{T}_{\mathrm{c}}=117^{\circ} \mathrm{C}\right)$ for $\mathrm{M} 1$ was higher than the corresponding values for $\mathrm{M} 2\left(\mathrm{~T}_{\mathrm{m}}=148^{\circ} \mathrm{C}\right.$ and $\mathrm{T}_{\mathrm{c}}=96^{\circ} \mathrm{C}$; Figure S2). Although the hydrogen bonding of the amide groups on M2 was expected to increase the temperature of thermal processes, these interactions could also have an adverse effect on the $\pi-\pi$ intermolecular association of these conjugated compounds. Further evidence for the disruption of $\pi-\pi$ association by hydrogen bonding can be found in the UV-vis absorption and X-ray diffraction data (vide infra).

The morphologies of the films deposited from chloroform solution of M1 and M2 were studied by atomic force microscopy (AFM) (Figure 4). M2 showed fibrous structure due to the intermolecular hydrogen bonding while the film of M1 did not. All these experiments indicated that the amide group of M2 has significant effects on the aggregation behavior of the dye and thus the film morphology. The nanowire-like fibrous structures of M2 might be advantageous for $\mathrm{BHJ}$ solar cells ${ }^{6} .{ }^{1} \mathrm{H}$ NMR dilution experiment of $\mathrm{PC}_{61} \mathrm{MBA}$ also exhibited slight chemical shift change of the amide proton (Figure $\mathrm{S} 1)$. The IR spectra of $\mathrm{PC}_{61} \mathrm{MBA}$ showed a $\mathrm{N}-\mathrm{H}$ stretching frequency at $3299 \mathrm{~cm}^{-1}$ which was distinctive for hydrogen bonded amide groups $^{19}$.

The optical and electrochemical properties. The UV-vis absorption spectra of the small molecules M1 and M2 are shown in Figure 5a. M1 and M2 had very similar absorption in chloroform except that the absorption of M1 was a little red shifted due to the more electron withdrawing property of the ester group. However, the absorption in solid films was quite different for M1 and M2 (Figure 5a). The maximum absorption of M2 in solid film is at $560 \mathrm{~nm}$ which was only red shifted $60 \mathrm{~nm}$ compared to solution absorption (Table 1). M1 displayed maximum absorption at $640 \mathrm{~nm}$ in solid film which is red shifted $130 \mathrm{~nm}$ compared to the solution absorption maximum. The difference in solid film absorption could be attributed to different aggregation resulting from the presence or absence of hydrogen bonding ${ }^{15,16,31}$. It is likely that the amide hydrogen bonding in compound M2 is disrupting close $\pi-\pi$ stacking between the conjugated planar molecules resulting in less red shifted absorption compared to the UV-vis absorption characteristics of compound M1. This is in agreement with data from the grazing incidence wide-angle X-ray scattering (GIWAXS) experiment which showed stronger $\pi-$ $\pi$ stacking molecular order for compound M1 compared with M2 (vide infra). The UV-vis absorption spectra of $\mathrm{PC}_{61} \mathrm{BM}$ and $\mathrm{PC}_{61} \mathrm{MBA}$ are shown in Figure $5 \mathrm{~b}$. The amide derivative showed<smiles>CCCCCc1cc(Br)sc1-c1cc(CCCCC)c(-c2ccc(C=O)s2)s1</smiles>

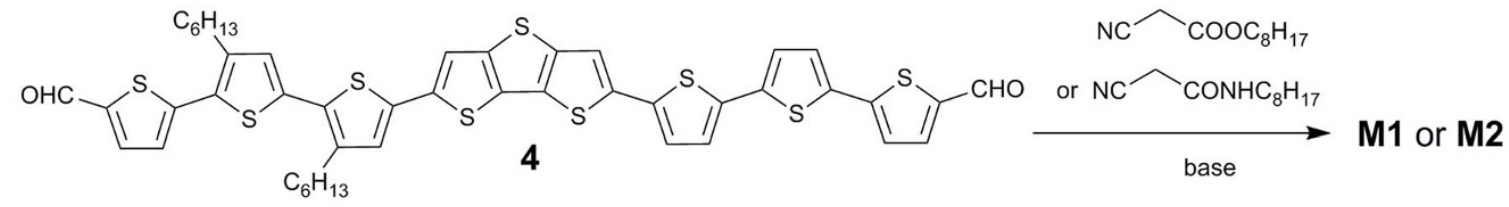

Figure $2 \mid$ Synthesis of small molecules M1 and M2. 


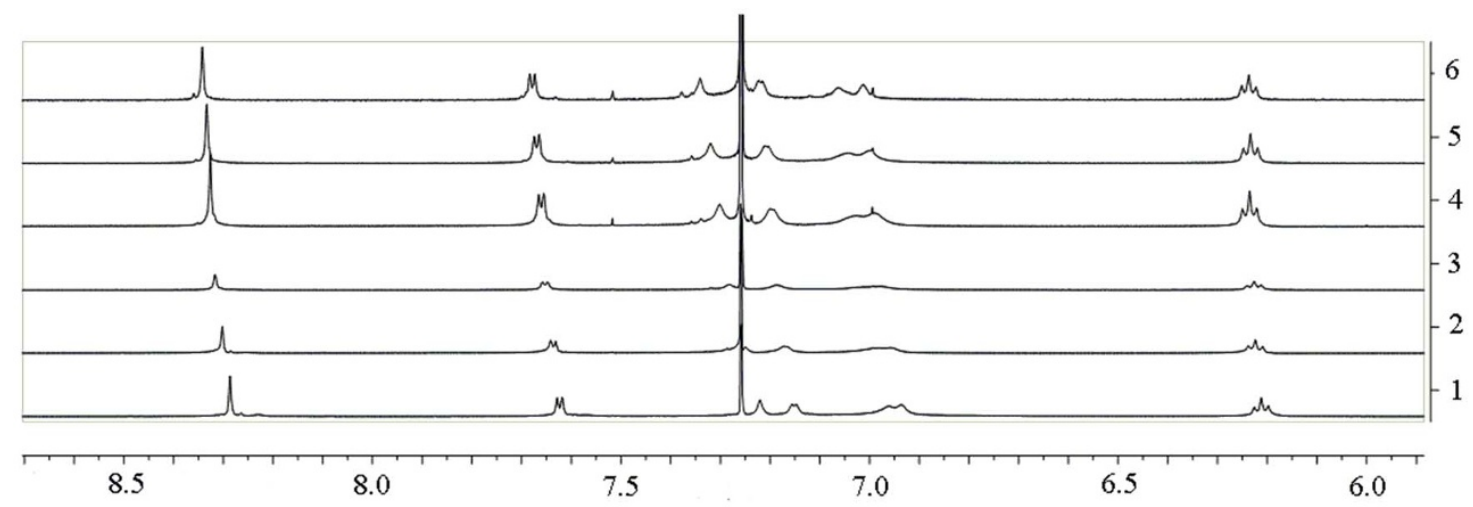

Figure 3 Partial ${ }^{1} \mathrm{H}$ NMR spectra of $\mathrm{M} 2$ in $\mathrm{CDCl}_{3}$ at different concentration. (From bottom to top: 1, $14 \mathrm{mM} ; 2,10 \mathrm{mM} ; 3,7 \mathrm{mM} ; 4,5 \mathrm{mM} ; 5,3.5 \mathrm{mM}$; 6, $1.8 \mathrm{mM}$, respectively).

sharp peak at $328 \mathrm{~nm}$ which was identical to that of $\mathrm{PC}_{61} \mathrm{BM}$. Broad peaks ranging from 450 to $650 \mathrm{~nm}$ were also observed.

The solution and thin film photoluminescence (PL) spectrum of the electron donor materials M1 and M2 were recorded (Figure S3a). The emission maximum for M1 and M2 in chloroform solution were $665 \mathrm{~nm}$ and $640 \mathrm{~nm}$ respectively with excitation wavelength at $500 \mathrm{~nm}$ (Table 1). Both M1 and M2 showed very weak emission in solid state with $550 \mathrm{~nm}$ excitation (Figure S3 and Table 1). The weak fluorescence of these compounds in thin films is probably a result of self-quenching with both materials showing strong intermolecular association. The photophysical properties of blend films of M1 and M2 with fullerene acceptors were also examined (Figure S3b and S4). No emission was detected in blend films of M1 and M2 with fullerene acceptors indicating charge transfer between the electron donor and electron acceptor materials upon excitation of the blend films.
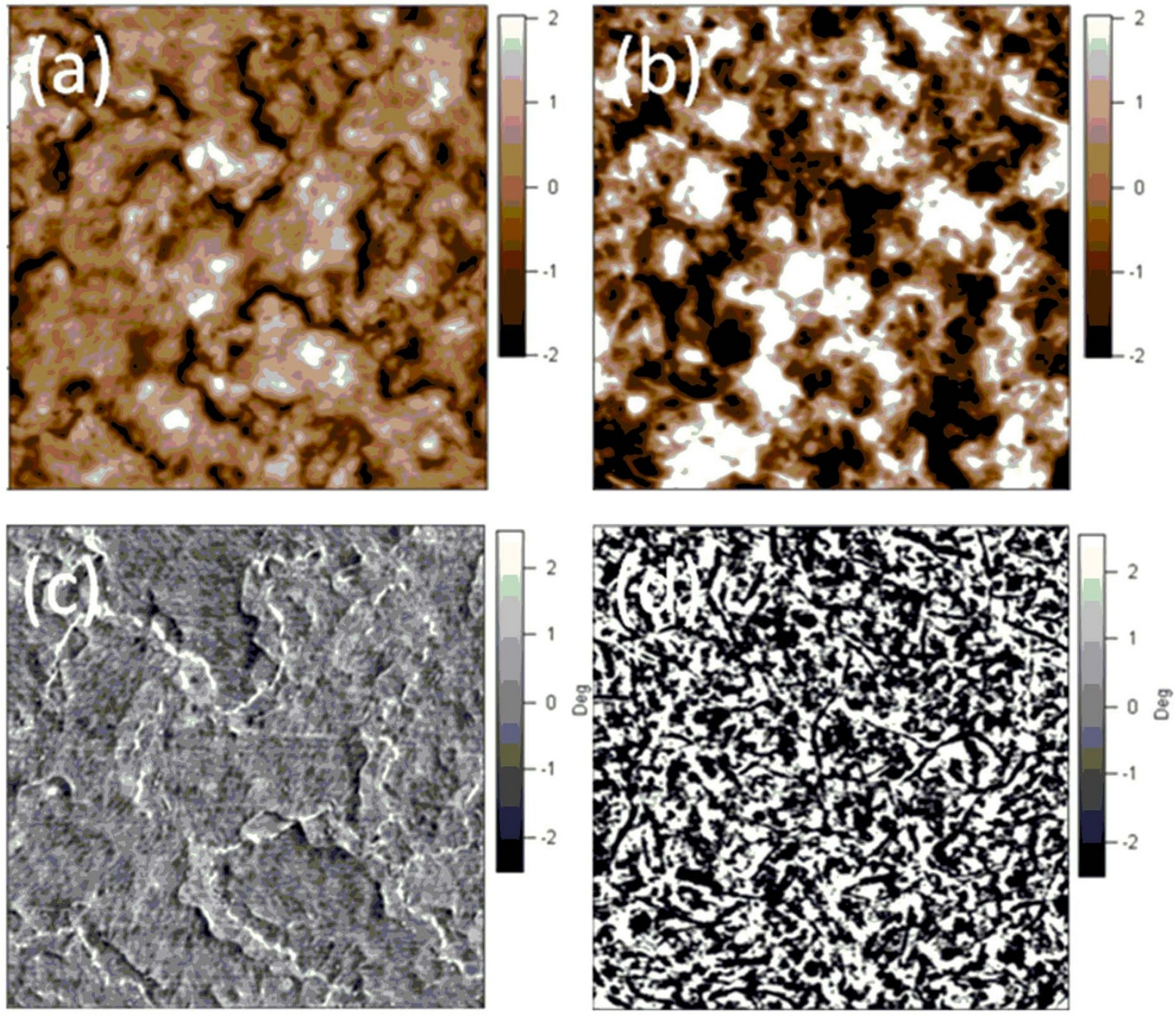

Figure $4 \mid$ AFM images of spin coated films from $10 \mathrm{mg} \mathrm{mL}^{-1}$ chloroform solution of M1 (a and c) and M2 (b and d). (a) and (b) are height images; (c) and (d) are phase images. Images are $2 \times 2 \mu \mathrm{m}$. 

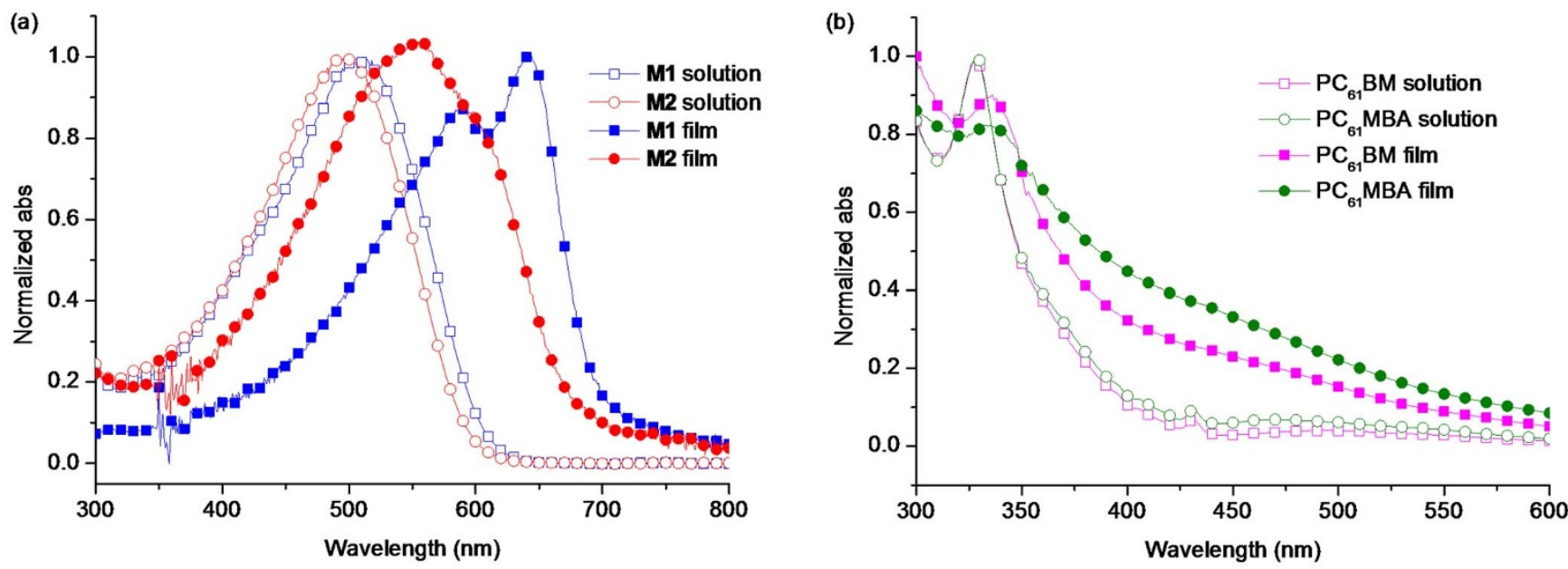

Figure 5 UV-Vis absorption spectra of (a) $\mathrm{M} 1$ and $\mathrm{M} 2$, (b) $\mathrm{PC}_{61} \mathrm{BM}$ and $\mathrm{PC}_{61} \mathrm{MBA}$ in chloroform solution (solid line) and in solid films (dash line).

Cyclic voltammetry (CV) was performed to determine the HOMO energy levels of M1 and M2 (Figure S5). From the value of the onset oxidation potential, the HOMO energy levels were determined to be $-5.09 \mathrm{eV}$ and $-5.01 \mathrm{eV}$ for M1 and M2, respectively. The HOMO and LUMO level of $\mathrm{PC}_{61} \mathrm{MBA}$ are -5.74 and $-3.80 \mathrm{eV}$, respectively, which were nearly the same as that of $\mathrm{PC}_{61} \mathrm{BM}$ (Table 1). The similarity of the electrochemical properties of the two donors as well as the two acceptors made them very suitable for comparing the influence of hydrogen bonding on solar cells performance in which the influence of different frontier orbital energy levels can be excluded.

The photovoltaic performance of the BHJ solar cells. The photovoltaic properties of the two small molecular donors were investigated in BHJ solar cells with conventional device architecture [ITO/ PEDOT:PSS/active layer/ZnO/Al] (Figure S7). Chloroform was chosen as the processing solvent due to its good solvent properties ${ }^{23}$. The weight ratios of small molecules and acceptor were varied to balance the absorbance and the charge transporting network of the photoactive layer. Common optimization parameters such as spinning rates (film thickness) were also investigated (SI, Table S1-S3). The devices were tested under the illumination of AM $1.5 \mathrm{G}, 100 \mathrm{~mW} \mathrm{~cm}{ }^{-2}$. The current density-voltage curves are displayed in Figure 6a and the photovoltaic performance parameters are listed in Table 2.

With the optimized weight ratio of $\mathrm{M} 1$ to $\mathrm{PC}_{61} \mathrm{BM}$ at $1: 2$, a power conversion efficiency (PCE) of $0.65 \%$ was obtained with an open circuit voltage $\left(V_{o c}\right)$ of $0.64 \mathrm{~V}$, a fill factor (FF) of $40 \%$ and a short circuit current density $\left(J_{s c}\right)$ of $2.55 \mathrm{~mA} \mathrm{~cm}^{-2}$. The active layers were also investigated by using $\mathrm{PC}_{71} \mathrm{BM}$ as the electron acceptor, which has a higher absorption coefficient in visible range ${ }^{32}$. The device with M1:PC $\mathrm{P} B \mathrm{BM}(1: 2)$ as active layer exhibited improved PCE of $1.15 \%$ with a higher $J_{s c}$ of $3.90 \mathrm{~mA} \mathrm{~cm}{ }^{-2}$, a higher FF of $47 \%$ and a $V_{o c}$ of $0.64 \mathrm{~V}$. It is clear from the external quantum efficiency (EQE) spectrum that there was a significant increase in contribution to the photocurrent from the fullerene acceptor as a result of using $\mathrm{PC}_{71} \mathrm{BM}$ (Figure 6b). In fact, the $\mathrm{EQE}$ spectrum for all the devices indicate that the fullerene acceptor was providing a large portion of the photocurrent contribution. The amide containing small molecule M2 was also tested and a maximum PCE of $0.30 \%$ was recorded with the optimized weight ratio of $\mathrm{M} 2$ to $\mathrm{PC}_{61} \mathrm{BM}$ at $1: 4$. Compared with the M1 based device, M2 based device showed lower $J_{s c}$ of $1.10 \mathrm{~mA}$ $\mathrm{cm}^{-2}$ and lower FF which could be attributed to the unfavorable morphology induced by the intermolecular hydrogen bonding of M2 as evidenced by morphological studies (vide infra). The replacement of $\mathrm{PC}_{61} \mathrm{BM}$ with $\mathrm{PC}_{71} \mathrm{BM}$ also yielded a higher PCE $(0.40 \%)$ mainly due to an improved $J_{s c}\left(1.30 \mathrm{~mA} \mathrm{~cm}^{-2}\right)$. However, the performance of the M2: $\mathrm{PC}_{71} \mathrm{BM}$ based device was lower than that of the M1:PC ${ }_{71} \mathrm{BM}$ based device. The hole mobility values for donor compounds M1 and M2 were measured using space charge limited current technique (see Supplementary Information for details). Hole-only devices were assembled with blends of the donor compounds with $\mathrm{PC}_{61} \mathrm{BM}$. The calculated hole mobilities were $6.3 \times 10^{-6} \mathrm{~cm}^{2} \mathrm{~V}^{-1} \mathrm{~s}^{-1}$ and $1.1 \times 10^{-6} \mathrm{~cm}^{2} \mathrm{~V}^{-1} \mathrm{~s}^{-1}$ for M1 and M2 respectively. These mobility values are in agreement with the UV-vis absorption and GIWAXS data as well as the observed solar cell device performance. The UV-vis absorption and GIWAXS data indicate compound M1 showed stronger $\pi-\pi$ stacking molecular order in solid state. Closed packing of conjugated organic semiconductor molecules often lead to better charge transport properties of the material. Better charge transport in the active layer blends of solar cell devices often result in improved device performance especially in combination with favorable blend film morphology.

The amide containing acceptor, $\mathrm{PC}_{61} \mathrm{MBA}$, was then used to replace its PCBM analogues. Interestingly, the PCE of devices based on M1: $\mathrm{PC}_{61} \mathrm{MBA}(1: 2)$ and M2: $\mathrm{PC}_{61} \mathrm{MBA}(1: 2)$ decreased sharply to $0.012 \%$ and $0.004 \%$, respectively. Extremely low $J_{s c}$ and $V_{o c}$ were

Table 1 | The optical properties and electronic energy levels of $M 1, M 2, \mathrm{PC}_{61} \mathrm{BM}$ and $\mathrm{PC}_{61} \mathrm{MBA}$

\begin{tabular}{|c|c|c|c|c|c|c|}
\hline Small molecule & $U V$-vis $\lambda_{\max }(\mathrm{nm})^{a}$ & $U V$-vis $\lambda_{\text {onset }}(\mathrm{nm})^{a}$ & $\mathrm{PL} \lambda_{\max }(\mathrm{nm})^{b}$ & Optical gap $(e V)^{c}$ & $\mathrm{E}_{\mathrm{HOMO}}(\mathrm{eV})^{d}$ & $E_{\text {LUMO }}(\mathrm{eV})$ \\
\hline M1 & $510(640)$ & 604 (693) & $665(726)$ & 1.79 & -5.09 & $-3.30^{e}$ \\
\hline M2 & $500(560)$ & $590(675)$ & 640 (710) & 1.84 & -5.01 & $-3.17^{e}$ \\
\hline $\mathrm{PC}_{6}, \mathrm{BM}$ & $328(336)$ & - & - & - & -5.76 & $-3.84^{d}$ \\
\hline
\end{tabular}

aUV-vis absorption data in chloroform solution and solid films in brackets.

bphotoluminescence (PL) data in chloroform solution and solid films in brackets.

ccalculated from thin film absorption onset.

${ }^{\mathrm{D}}$ Measured using CV.

ecalculated from HOMO and the optical gap. 

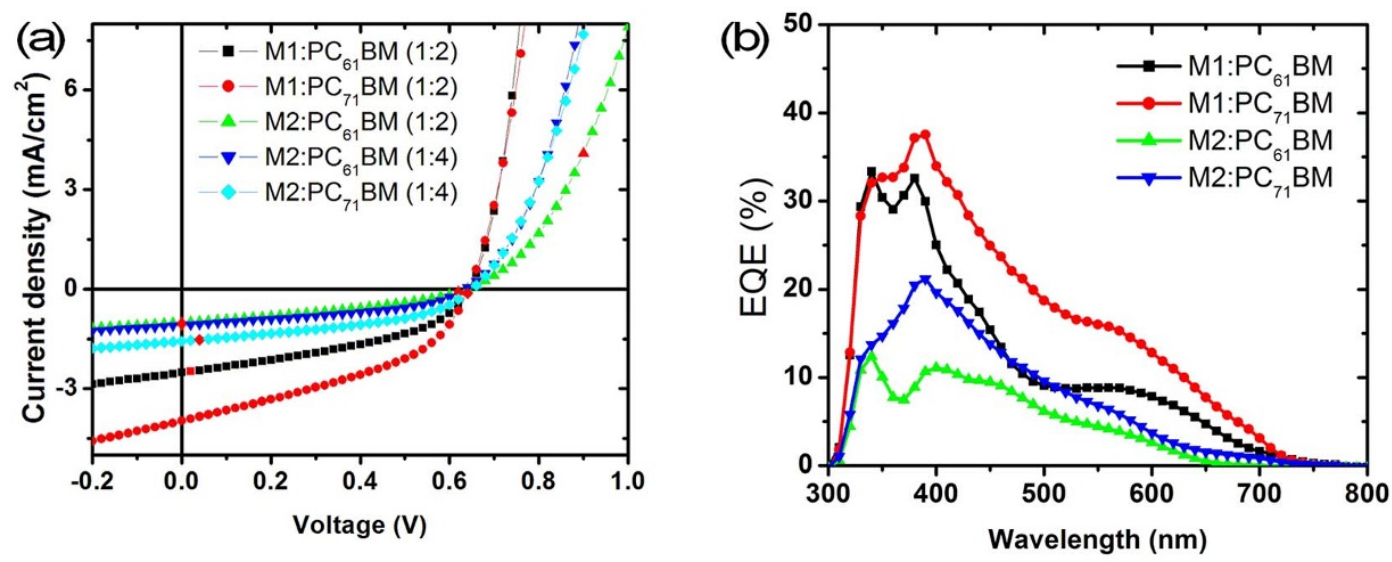

Figure 6 (a) Current density vs. voltage data and (b) external quantum efficiency (EQE) spectrum for devices containing compounds M1 and M2.

observed even though $\mathrm{PC}_{61} \mathrm{MBA}$ has very similar absorption and LUMO energy level to $\mathrm{PC}_{61} \mathrm{BM}$. Optimization of donor-acceptor blend ratios did not provide any significant improvement in device performance (SI, Table S3).

Morphological studies. Previous literature reported that amide fullerene derivatives induced large-scale phase separation and serious aggregations ${ }^{19}$. It was likely that the poor performance of $\mathrm{PC}_{61} \mathrm{MBA}$ was also related to the undesirable active layer morphology. Morphology of the active layers was investigated using tapping mode AFM. The height as well as phase images of M1:PC ${ }_{61} \mathrm{BM}, \mathrm{M} 2: \mathrm{PC}_{61} \mathrm{BM}, \mathrm{M} 1: \mathrm{PC}_{61} \mathrm{MBA}$, and M2:PC ${ }_{61} \mathrm{MBA}$ blends (donor/acceptor ratio $1: 2$ ) at optimized conditions are shown in Figure 7. From the phase images of the $\mathrm{PC}_{61} \mathrm{BM}$ based blend, interpenetrating networks can be observed indicating welldefined nanoscale phase separation and efficient percolation channels. Compared to the active layer of $\mathrm{M} 2: \mathrm{PC}_{61} \mathrm{BM}$ which gave low $J_{s c}$ and low FF, M1:PC ${ }_{61} \mathrm{BM}$ active layer also displayed smoother surface morphology (for $\mathrm{M} 1: \mathrm{PC}_{61} \mathrm{BM}$ blend, $\mathrm{rms}=0.41 \mathrm{~nm}$; for $\mathrm{M} 2: \mathrm{PC}_{61} \mathrm{BM}$ blend, $\mathrm{rms}=0.46 \mathrm{~nm}$ ) and smaller domain sizes (typical domain size for $\mathrm{M1}: \mathrm{PC}_{61} \mathrm{BM}$ blend, $17-30 \mathrm{~nm}$; $\mathrm{M1}: \mathrm{PC}_{61} \mathrm{BM}$ blend, $28-50 \mathrm{~nm}$ ). Larger phase domain sizes in the $\mathrm{M} 2: \mathrm{PC}_{61} \mathrm{BM}$ blend was likely a result of the intermolecular hydrogen bonding and strong aggregation of M2. This result was also consistent with previous reports in which smoother blend films and smaller domain sizes gave better performance in bulk heterojunction solar cells ${ }^{23,32}$. Large-scale phase separation and aggregation were observed when $\mathrm{PC}_{61} \mathrm{MBA}$ was used in the $\mathrm{BHJ}$ solar cells. Sectional analysis of Figure $7 \mathrm{c}$ and $7 \mathrm{~d}$ verified the aggregation with size up to hundreds of nanometers in width, and several tens of nanometers in height. The aggregation was attributed to the strong hydrogen bonding between $\mathrm{PC}_{61} \mathrm{MBA}$ itself as well as

Table 2 | Device performance parameters of $\mathrm{BHJ}$ solar cells based on $M 1, M 2, P C B M$ and $\mathrm{PC}_{61} M^{M B A}$.

\begin{tabular}{|c|c|c|c|c|}
\hline Active layer & $V_{o c}(V)$ & $J_{s c}\left(\mathrm{~mA} \mathrm{~cm}^{-2}\right)$ & $\mathrm{FF}(\%)$ & PCE (\%) \\
\hline M1:PC ${ }_{61} \mathrm{BM}(1: 2)$ & $0.64 \pm 0.1$ & $2.55 \pm 0.2$ & $40 \pm 4$ & $0.65 \pm 0.10$ \\
\hline $\mathbf{M 1}: \mathrm{PC}_{71} \mathrm{BM}(1: 2)$ & $0.64 \pm 0.1$ & $3.90 \pm 0.2$ & $47 \pm 5$ & $1.15 \pm 0.15$ \\
\hline M2: $\mathrm{PC}_{61} \mathrm{BM}(1: 2)$ & $0.62 \pm 0.2$ & $1.00 \pm 0.1$ & $34 \pm 2$ & $0.20 \pm 0.04$ \\
\hline M2: $\mathrm{PC}_{61} \mathrm{BM}(1: 4)$ & $0.62 \pm 0.1$ & $1.10 \pm 0.1$ & $40 \pm 3$ & $0.30 \pm 0.03$ \\
\hline M2:PC ${ }_{71} B M(1: 4)$ & $0.64 \pm 0.1$ & $1.30 \pm 0.2$ & $34 \pm 2$ & $0.40 \pm 0.05$ \\
\hline M1:PC ${ }_{61} M B A(1: 2)$ & 0.19 & 0.19 & 32 & 0.012 \\
\hline M2:PC ${ }_{61} M B A(1: 2)$ & 0.14 & 0.09 & 30 & 0.004 \\
\hline
\end{tabular}

${ }^{a}$ All devices were fabricated in air. Average values of 10 devices are shown with standard deviation. the hydrogen bonding between $\mathrm{PC}_{61} \mathrm{MBA}$ and the small molecule donor since the active layer were spin casted from homogenous solution ${ }^{19}$. The low performance of $\mathrm{PC}_{61} \mathrm{MBA}$ devices was a direct result of large scale phase separation which was unfavorable for exciton diffusion and charge separation.

Grazing incidence wide angle X-ray scattering (GIWAXS) studies. GIWAXS is a widely used technique to determine crystal packing and structural orientation of donor and acceptor blend films ${ }^{33}$. From the GIWAXS patterns presented in Figure 8a, the crystalline nature of M1 in the pristine film is evident which exhibited strong (100) Bragg reflection peak at $\mathrm{q}=0.43 \AA^{-1}$ and (200) Bragg reflection peak at $\mathrm{q}=$ $0.86 \AA^{-1}$ corresponding to $d$-spacing values of $14.6 \AA$ and $7.3 \AA$, respectively. The reflection at $\mathrm{q}=1.80 \AA^{-1}$ was attributed to the $\pi$ $-\pi$ stacking distance. In great contrast, the pristine film of M2 displayed very weak reflection peak at $\mathrm{q}=0.42 \AA^{-1}$ indicating a lower degree of order. Similar (100) and (200) reflection peak was observed in the M1:PC ${ }_{61} \mathrm{BM}(1: 2)$ blend film indicating the addition of $\mathrm{PC}_{61} \mathrm{BM}$ did not change the crystalline nature of $\mathrm{M} 1$. The broad diffraction ring centered at $\mathrm{q}=1.35 \AA^{-1}$ was arising from $\mathrm{PC}_{61} \mathrm{BM}^{28}$. For the M2:PC ${ }_{61} \mathrm{BM}(1: 2)$ blend film, only the reflection of $\mathrm{PC}_{61} \mathrm{BM}$ (broad reflection centered at $\mathrm{q}=1.35 \AA^{-1}$ ) was observed suggesting that the amide group of $\mathrm{M} 2$ has interaction with $\mathrm{PC}_{61} \mathrm{BM}$ and thus changed the packing mode of the small molecular donor (Figure 8b). The M2: $\mathrm{PC}_{61} \mathrm{BM}$ blend films displayed different scattering patterns probably due to the aggregation of $\mathrm{PC}_{61} \mathrm{BM}$ and also the interaction of $\mathrm{M} 2$ and $\mathrm{PC}_{61} \mathrm{BM}$. Presumably the introduction of hydrogen bonding can decrease orientation order and lead to increased packing frustration relative to $\mathrm{M} 1: \mathrm{PC}_{61} \mathrm{BM}$.

\section{Conclusion}

Two small molecular donor materials, one end capped with ester group and the other end capped with amide group, were synthesized and fully characterized. The amide group of the donor material M2 formed intermolecular hydrogen bonds which led to fibrous aggregates in solid state. Application of the two small molecular donor materials in $\mathrm{BHJ}$ solar cells revealed that the amide group containing donor material showed lower performance due to the hydrogen bonding induced aggregation and disadvantageous morphology. Replacement of PCBM with its amide analogue further increased aggregation and large scale phase separation was observed in the blend films. Well defined morphology ${ }^{34-36}$, enhanced stability ${ }^{22,35}$, improved performance ${ }^{18-22,34,37-39}$ have been discussed in the literature for materials with hydrogen bonding moieties. In this work, the results clear showed that a cautious approach must be taken when using strong intermolecular forces such as hydrogen bonding in organic solar cell materials. 

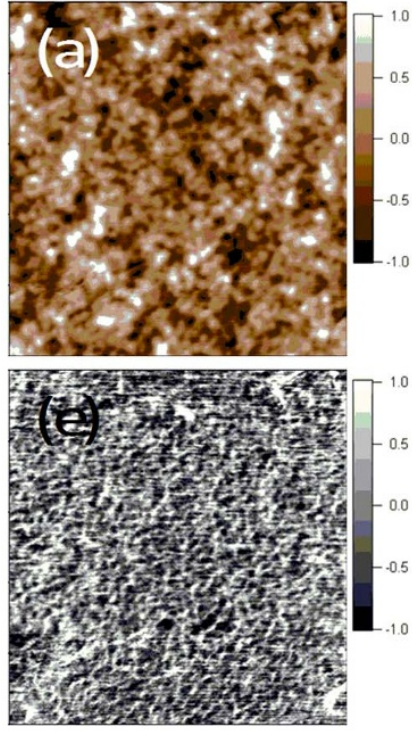
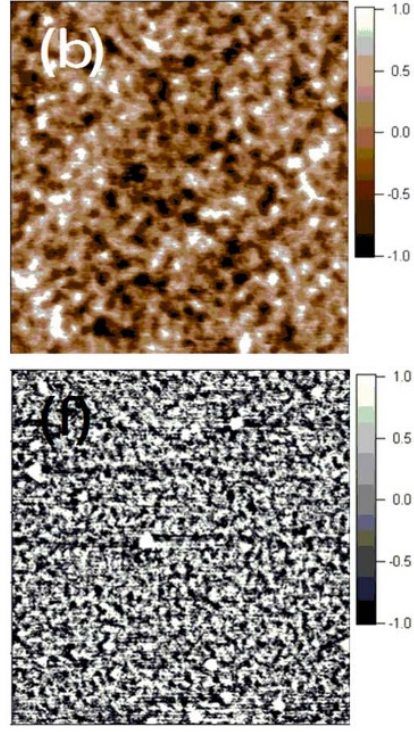
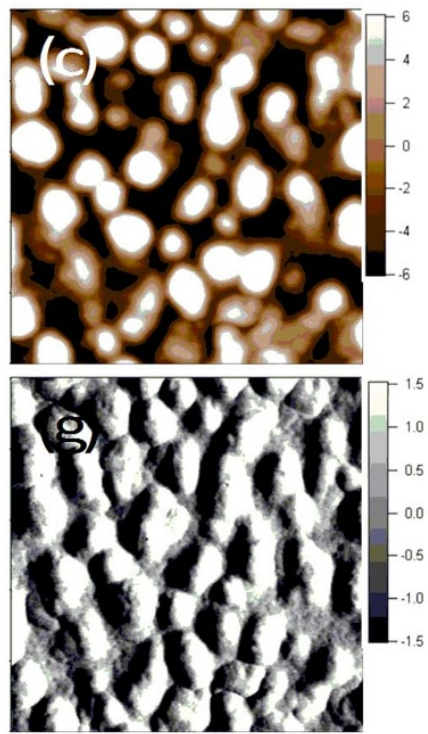
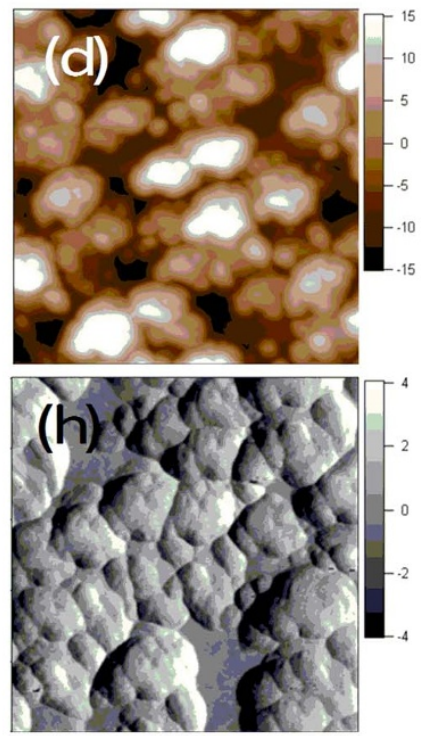

Figure 7 | AFM images of films spin coated from M1:PC ${ }_{61} \mathrm{BM}$ (a and e), M2:PC ${ }_{61} \mathrm{BM}$ (b and f), $\mathrm{M1}: \mathrm{PC}_{61} \mathrm{MBA}\left(\mathrm{c}\right.$ and $\mathrm{g}$ ), and $\mathrm{M} 2: \mathrm{PC}{ }_{61} \mathrm{MBA}(\mathrm{d}$ and $\mathrm{h}$ ). (a), (b), (c) and (d) are height images; (e), (f), (g) and (h) are phase images. All images are $1 \times 1 \mu \mathrm{m}$.

\section{Methods}

Materials. Small molecules M1 and M2 are synthesized following the procedure described in SI (Scheme S1). $\mathrm{PC}_{61} \mathrm{MBA}$ was synthesized following a modified literature procedure (Scheme $\mathrm{S} 2$ ). $\mathrm{PC}_{61} \mathrm{BM}$ and $\mathrm{PC}_{71} \mathrm{BM}$ were purchased from Nano-C, Inc.

BHJ solar cells fabrication. BHJ solar cells were processed on pre-patterned indium tin oxide (ITO) coated glass substrates with a sheet resistance of $15 \Omega$ per square. First a thin layer $(30 \mathrm{~nm})$ of poly(3,4-ethylenedioxythiophene):poly(styrenesulfonate) (PEDOT:PSS; Baytron AI 4083 from HC Starck) was spin-coated on a UV-Ozone cleaned ITO substrates, followed by baking on a hot plate at $140^{\circ} \mathrm{C}$ for $10 \mathrm{~min}$. An active layer of the device was deposited by spin coating a chloroform solution containing $10 \mathrm{mg}$ of donor and $20 \mathrm{mg}$ of acceptor. The thickness of the active layer was $75 \mathrm{~nm}$ as determined by Veeco Dektak 150+ Surface Profiler. A thin layer of
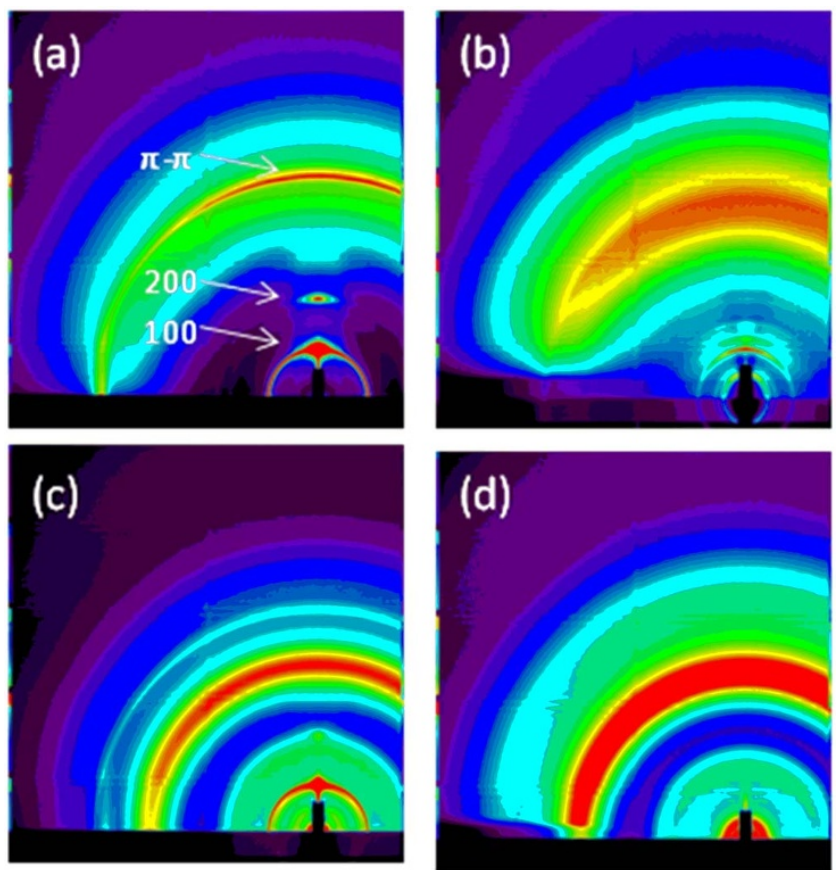

Figure 8 GIWAXS images of (a) pristine film of M1, (b) pristine film of M2, (c) M1:PC ${ }_{61} \mathrm{BM}$ blend film and (d) M2:PC ${ }_{61} \mathrm{BM}$ blend film. Performed at the Australian Synchrotron (Beam centre: 215.1, 968.2) at an incident angle of $0.10^{\circ}$.
$\mathrm{ZnO}$ nanopaticle was deposited on the active layer by spin-coating (3000 rpm) to form a $25 \mathrm{~nm}$ thick $\mathrm{ZnO}$ layer. The films were then transferred to a metal evaporation chamber and aluminum $(100 \mathrm{~nm}$ ) were deposited through a shadow mask (active area was $0.1 \mathrm{~cm}^{2}$ ) at approximately $1 \times 10^{-6}$ torr. Film thickness was determined by Veeco Dektak 150+ Surface Profiler. The current density-voltage measurements of the devices were carried out using a $1 \mathrm{~kW}$ Oriel solar simulator with an AM $1.5 \mathrm{G}$ filter as the light source in conjunction with a Keithley 2400 source measurement unit. Solar measurements were carried out under $1000 \mathrm{~W} / \mathrm{m}^{2}$ AM 1.5 G illumination conditions. For accurate measurement, the light intensity was calibrated using a reference silicon solar cell (PV measurements Inc.) certified by the National Renewable Energy Laboratory. Device fabrication and characterizations were performed in an ambient environment without any encapsulation.

1. Yu, G., Gao, J., Hummelen, J. C., Wudl, F. \& Heeger, A. J. Polymer photovoltaic cells: Enhanced efficiencies via a network of internal donor-acceptor heterojunctions. Science 270, 1789-1791 (1995).

2. Nagarjuna, G. \& Venkataraman, D. Strategies for controlling the active layer morphologies in OPVs. J. Polym. Sci., Part B: Polym. Phys. 50, 1045-1056 (2012).

3. Benanti, T. L. \& Venkataraman, D. Organic solar cells: An overview focusing on active layer morphology. Photosynthesis Research 87, 73-81 (2006).

4. Bavel, S., Veenstra, S. \& Loos, J. On the importance of morphology control in polymer solar cells. Macromol. Rapid Commun. 31, 1835-1845 (2010).

5. Yang, X. \& Loos, J. Toward high-performance polymer solar cells: The importance of morphology control. Macromolecules 40, 1353-1362 (2007).

6. Thompson, B. C. \& Frechet, J. M. J. Polymer-fullerene composite solar cells. Angew. Chem. Int. Ed. 47, 58-77 (2008).

7. Coakley, K. M. \& McGehee, M. D. Conjugated polymer photovoltaic cells. Chem. Mater. 16, 4533-4542 (2004)

8. Kang, S. J. et al. Using self-organization to control morphology in molecular photovoltaics. J. Am. Chem. Soc. 135, 2207-2212 (2013).

9. Mayer, A. C. et al. Bimolecular crystals of fullerenes in conjugated polymers and the implications of molecular mixing for solar cells. Adv. Funct. Mater. 19, 1173-1179 (2009).

10. Kennedy, R. et al. Self-assembling fullerenes for improved bulk-heterojunction photovoltaic devices. J. Am. Chem. Soc. 130, 17290-17292 (2008).

11. Wong, W. W. H. et al. Fluorenyl hexa-peri-hexabenzocoronene-dendritic oligothiophene hybrid materials: synthesis, photophysical properties, selfassociation behaviour and device performance. Chem. Eur. J. 17, 5549-5560 (2011).

12. Wong, W. W. H. et al. Self-assembling thiophene dendrimers with a hexa-perihexabenzocoronene core-synthesis, characterization and performance in bulk heterojunction solar cells. Chem. Mater. 22, 457-466 (2010).

13. Kumar, R. J. et al. Hierarchical self-assembly of semiconductor functionalized peptide $\alpha$-helices and optoelectronic properties. J. Am. Chem. Soc. 133, 8564-8573 (2011).

14. Emsley, J. Very strong hydrogen bonding. Chem. Soc. Rev. 9, 91-124 (1980),

15. Prins, L. J., Reinhoudt, D. N. \& Timmerman, P. Noncovalent synthesis using hydrogen bonding. Angew. Chem. Int. Ed. 40, 2382-2426 (2001).

16. Schenning, A. P. H. J. et al. Photoinduced electron transfer in hydrogen-bonded oligo(p-phenylene vinylene)-perylene bisimide chiral assemblies. J. Am. Chem. Soc. 124, 10252-10253 (2002). 
17. Glowacki, E. D. et al. Hydrogen-bonds in molecular solids - from biological systems to organic electronic. J. Mater. Chem. B 1, 3742-3753 (2013).

18. Lin, Y. et al. Morphology control in $\mathrm{TiO} 2$ nanorod/polythiophene composites for bulk heterojunction solar cells using hydrogen bonding. Macromolecules 45, 8665-8673 (2012)

19. Liu, C. et al. New methanofullerenes containing amide as electron acceptor for construction photovoltaic devices. J. Phys. Chem. C 113, 21970-21975 (2009).

20. Patra, D. et al. Enhancement of photovoltaic properties in supramolecular polymer networks featuring a solar cell main-chain polymer $\mathrm{H}$-bonded with conjugated cross-linkers. Polymer 53, 1219-1228 (2012).

21. Sahu, D. et al. Synthesis and application of $\mathrm{H}$-Bonded cross-linking polymers containing a conjugated pyridyl H-Acceptor side-chain polymer and various carbazole-based H-Donor dyes bearing symmetrical cyanoacrylic acids for organic solar cells. Polymer 51, 6182-6192 (2010).

22. Hsu, S. L. et al. New carbazole-based conjugated polymers containing pyridylvinyl thiophene units for polymer solar cell applications: Morphological stabilization through hydrogen bonding. J. Polym. Sci., Part A: Polym. Chem. 49, 603-611 (2011).

23. Zhou, J. et al. Small molecules based on benzo[1,2-b:4,5-b']dithiophene unit for high-performance solution-processed organic solar cells. J. Am. Chem. Soc. 134, 16345-16351 (2012).

24. Takacs, C. J. et al. Solar cell efficiency, self-assembly, and dipole-dipole interactions of isomorphic narrow-band-gap molecules. J. Am. Chem. Soc. 134, 16597-16606 (2012).

25. van der Poll, T. S. et al. Non-basic high-performance molecules for solutionprocessed organic solar cells. Adv. Mater. 24, 3646-3649 (2012).

26. Liu, Y. et al. Solution-processed small molecules using different electron linkers for high-performance solar Cells. Adv. Mater. 25, 4657-4662 (2013).

27. Fitzner, R. et al. Correlation of $\pi$-conjugated oligomer structure with film morphology and organic solar cell performance. J. Am. Chem. Soc. 134, 11064-11067 (2012)

28. Wang, H. et al. The role of additive in diketopyrrolopyrrole-based small molecular bulk heterojunction solar cells. Adv. Mater. DOI: 10.1002/adma.201301716 (2013).

29. Kwon, T. H. et al. Dithienothiophene (DTT)-based dyes for dye-sensitized solar cells: synthesis of 2,6-dibromo-DTT. J. Org. Chem. 76, 4088-4093 (2011).

30. Stals, P. J. M. et al. Asymmetrically substituted benzene-1,3,5-tricarboxamides: self-assembly and odd-even effects in the solid state and in dilute Solution. Chem. Eur. J. 15, 2071-2080 (2009).

31. Kajitani, T. et al. Liquid crystalline amides: linear arrangement of rod-like molecules by lateral intermolecular hydrogen bonding and molecular shape effect. J. Mater. Chem. 14, 3449-3456 (2004).

32. Liang, Y. Y. et al. Highly efficient solar cell polymers developed via fine-tuning of structural and electronic properties. J. Am. Chem. Soc. 131, 7792-7799 (2009).

33. Rivnay, J. et al. Quantitative determination of organic semiconductor microstructure from the molecular to device scale. Chem. Rev. 112, 5488-5519 (2012).

34. Yao, K. et al. Cooperative assembly donor acceptor system induced by intermolecular hydrogen bonds leading to oriented nanomorphology for optimized photovoltaic performance. J. Phys. Chem. C 116, 714-721 (2012).
35. Lin, Y. et al. Cooperative assembly of hydrogen-bonded diblock copolythiophene/ fullerene blends for photovoltaic devices with well-defined morphologies and enhanced stability. Chem Mater. 24, 622-632 (2012)

36. Lin, Y. H. et al. Supramolecular conjugated block copolymers. Macromolecules 45 , 6571-6579 (2012).

37. Fang, H. P. et al. Synthesis of novel dithienothiophene- and 2,7-carbazole-based conjugated polymers and $\mathrm{H}$-bonded effects on electrochromic and photovoltaic propertie. J. Polym. Sci., Part A: Polym. Chem. 50, 5011-5022 (2012).

38. Kumar, R. J. et al. Enhancement of efficiency in organic photovoltaic devices containing self-complementary hydrogen-bonding domains. Beilstein J. Org. Chem. 9, 1102-1110 (2013).

39. Ruiz-Carretero, A. et al. Stepwise self-assembly to improve solar cell morphology. J. Mater. Chem. A 1, 11674-11681 (2013).

\section{Acknowledgments}

This work was made possible by support of the Victorian Organic Solar Cell Consortium, with funding provided by the Victorian State Government Department of State Development, Business and Innovation (Energy Technology Innovation Strategy and Victorian Science Agenda) and the Australian Renewable Energy Agency (ARENA Project 2-A018). Dr W. H. H. Wong is supported by an Australian Research Council Future Fellowship (FT130100500). We thank Andrew B. Holmes for helpful discussion. We thank the Australian Synchrotron for the SAXS/WAXS beam time to perform the GIWAXS experiments.

\section{Author contributions}

Z.X. synthesized and characterized the materials. Z.X. and W.W.H.W. prepared the manuscript. K.S. performed morphological studies and device fabrication. J.S. and S.J. did device fabrication. D.J.J. and W.W.H.W. supervised the project. All authors analyzed the data, discussed the results and contributed to revisions.

\section{Additional information}

Supplementary information accompanies this paper at http://www.nature.com/ scientificreports

Competing financial interests: The authors declare no competing financial interests.

How to cite this article: Xiao, Z. et al. Hydrogen bonding in bulk heterojunction solar cells: A case study. Sci. Rep. 4, 5701; DOI:10.1038/srep05701 (2014).

This work is licensed under a Creative Commons Attribution-NonCommercialNoDerivs 4.0 International License. The images or other third party material in this article are included in the article's Creative Commons license, unless indicated otherwise in the credit line; if the material is not included under the Creative Commons license, users will need to obtain permission from the license holder in order to reproduce the material. To view a copy of this license, visit http:// creativecommons.org/licenses/by-nc-nd/4.0/ 